\title{
The Nature of Policy-Making in Universities
}

\author{
WILLIAM H. TAYLOR*
}

\begin{abstract}
Policy-making in universities has been characterized in a variety of ways. The bureaucratic, collegial, political, and organized anarchy models have all been proposed as descriptions of the process. Although each of these models is useful in the study of university policy-making, they fail to provide a complete explanation of the phenomenon. An alternate approach to the conceptualization and analysis of policy-making is proposed and applied to a recent case at The University of Calgary. The proposed model describes policy-making as a set of "policymaking systems" each of which is temporary in nature and develops in response to an identifiable stress in the institutional environment.
\end{abstract}

\section{RÉSUMÉ}

Dans les universités, la formulation de la politique se fait de différentes façons. Ont été proposés les modèles bureaucratique, collégial, politique et anarchie organisée. Quoique chacun ait apporté sa contribution à la recherche dans ce domaine, tous n'arrivent pas à expliquer complètement le phénomène. Cet article propose une approche différente et l'applique à un cas bien particulier: l'Université de Calgary. Le modèle comprend un ensemble de "systèmes de formulation de la politique" dont chaque système est provisoire et répond à une force reconnaissable dans le milieu institutionnel.

\section{INTRODUCTION}

Policy-making activities in large complex organizations, such as universities, have been described through the application of a variety of models. Early theorists in the study of organizations tended to accept the bureaucratic model with its implicit rational model of decision-making as the most applicable. It was presumed that incumbents in the formal positions of the organization would have the prerequisite information, expertise and authority to make decisions relating to their

* Associate Professor of Continuing Education, The University of Calgary 
areas of responsibility. Policy-making in this organizational model is viewed not only as a rational process but as an individualized activity undertaken by the person who had been assigned the responsibility for overseeing that particular part of the operation. The decision-maker goes through the rational process of judging the merits of alternative solutions to each problem and selects the alternative which maximizes the goals of the organization. This clear-cut, somewhat simplistic model of policy-making was found to have obvious limitations when applied to university organizations and other approaches have been proposed.

Rather than describing the university as a bureaucracy, Millett (1962) suggested it be viewed as a community of individuals and groups all of whom may have different roles and specialties but who share common goals and objectives for the organization. He referred to this as the "collegial" model and suggested that the decision-making process could be described as one of "consensus". It was presumed that even though differences of immediate goals of groups such as faculty, administration and students might surface during decision-making, these differences would be overridden by the fundamental agreement concerning the purpose and goals of the university organization. Inevitably, this rational consensus-seeking process would lead to policy decisions which would be in the best interests of the entire community.

An alternative to the collegial model was proposed by Baldridge (1971) who suggested that the "political system" model best described the policy-making process of the modern university. This view recognized that various identifiable groups such as administration, faculty, students and community trustees function as power blocks or interest groups, trying to influence decisions in such a way as to benefit their own membership. These groups have irreconcilable differences in objectives which can not be resolved through a consensual process but which must be accommodated through a system of confrontation, compromise, negotiation, and legislation. In such a system, decision-making is a diffused process with many individuals and groups which exert their influence or power through any number of both formal and informal channels. The process is not only more decentralized but also is much more complex than either the bureaucratic or collegial models. The political model is also more difficult to apply in a particular instance or institution since much of the significant activity takes place behind the scenes or through the subtle application of power. Nevertheless, the political model still is based on a high degree of rationality in which the various actors make decisions or exert influence guided by their own goals and objectives. It is implied that while solutions or decisions are logically related to recognized problems, the process by which solutions are agreed upon differs from either the bureaucratic or collegial approach.

This belief in the existence of rationality in university policy-making has been challenged on several fronts. Perhaps the best known proposal is from Cohen and March, (1974) who proposed that universities belong to a class of organizations they labelled as "organized anarchies." Such organizations share the following characteristics: (1) problematic goals - members cannot agree on organizational goals. "It can be described better as a loose collection of changing ideas than as 
a coherent structure" (1974:3); (2) unclear technology - the organization does not understand how it operates but rather learns by a trial-and-error process; and (3) fluid participation - "the participants in the organization vary among themselves in the time and effort they devote to the organization" (Cohen and March, 1974:3). Within such an organization decision-making can hardly be described as a rational process but rather is explained through the "garbage can" model. The analogy suggests that just as we find any number of objects at random in a garbage can we also have problems, solutions, participants and opportunities for decisions floating around in no particular order within an organization. Further, just as objects tend to stick to one another in a garbage can, problems and solutions become attached to each other in organizations. Rather than this joining of problems and solutions being a controlled, rational process, Cohen and March suggest that it happens on a random basis and that frequently the wrong solution is attached to a problem or perhaps if the right problem and solution are joined an opportunity to implement the decision does not occur and the solution and problem then become "unstuck" and continue to exist separately in the organization. In practice, this implies that although one individual in an organization may identify a problem and another may have a solution at hand, unless an opportunity exists or is created for these two to come together, a decision will not be made, or at least, a different decision will be made.

The major characteristics of these four models are summarized in Figure 1. While this description of policy-making models is not exhaustive, it does illustrate the variety of perceptions of organizational processes that exists within the modern university. What is also clear, is that based on the research that has been done to date, one cannot state with any confidence just what is an appropriate model for describing or analyzing the phenomenon of university policy-making. It was on the basis of this conclusion that the author began an in-depth analysis of a specific case in policy-making at The University of Calgary. The primary objectives of the study were to improve our understanding of the policy-making process in general, and to develop procedures or techniques for analyzing such processes.

\section{THE POLICY-MAKING SYSTEM MODEL}

The vehicle developed for the analysis of the case was termed the "Policy-Making System" (PMS) model. This model conceptualizes policy-making processes as "event systems" which possess the attributes of all systems as described in general systems theory. (von Bertalanffy, 1956: Miller, 1978.) Each PMS is considered a unique system which develops in response to an environmental pressure exerted on the organizational system. These pressures may be of many types (social, economic, political) but in any case will result in the identification of an issue which needs resolution or clarification through the development of a policy statement. Following the initial step (the identification of an issue) the PMS can develop in any number of ways involving many actors and both informal and formal groups or organizational structures. The final output of a successful PMS is a policy statement which is accepted by the legitimate authorities of the 


\begin{tabular}{|c|c|c|c|c|}
\hline & Bureaucratic & Collegial & Political & Organized Anarchy \\
\hline $\begin{array}{l}\text { Assumptions about } \\
\text { structure }\end{array}$ & Hierarchial bureaucracy & $\begin{array}{c}\text { Community of peers } \\
\qquad\end{array}$ & $\begin{array}{l}\text { Fragmented, complex } \\
\text { professional federation }\end{array}$ & $\begin{array}{l}\text { Lacks coherent structure; } \\
\text { unclear technology; structure } \\
\text { changes in response to } \\
\text { market demand for personnel, } \\
\text { heterogeneity of values, and } \\
\text { orqanizational slack }\end{array}$ \\
\hline Social characteristics & $\begin{array}{l}\text { Unitary: integrated by } \\
\text { formal system }\end{array}$ & $\begin{array}{l}\text { Unitary: integrated } \\
\text { by peer consensus }\end{array}$ & $\begin{array}{l}\text { Pluralistic: encompasses } \\
\text { different interest groups } \\
\text { with divergent values }\end{array}$ & $\begin{array}{l}\text { Pluralistic: problematic } \\
\text { goals: fluid participation } \\
\text { of members in decision- } \\
\text { making }\end{array}$ \\
\hline $\begin{array}{l}\text { Basic theoretical } \\
\text { foundations }\end{array}$ & $\begin{array}{l}\text { Weberian bureaucracy, } \\
\text { classic studies of } \\
\text { formal systems }\end{array}$ & $\begin{array}{l}\text { Professionalism } \\
\text { literature, human- } \\
\text { relations approach } \\
\text { to organization }\end{array}$ & $\begin{array}{l}\text { Conflict analysis, } \\
\text { interest group theory, } \\
\text { community power literature }\end{array}$ & $\begin{array}{l}\text { Simulation modelling, } \\
\text { organizational power } \\
\text { distribution }\end{array}$ \\
\hline $\begin{array}{l}\text { View of decision- } \\
\text { making process }\end{array}$ & $\begin{array}{l}\text { "Rational" decision- } \\
\text { making; standard oper- } \\
\text { ating procedures }\end{array}$ & $\begin{array}{l}\text { Shared collegial } \\
\text { decision: consensus, } \\
\text { community participation }\end{array}$ & $\begin{array}{l}\text { Negotiation, bargaining } \\
\text { political influence, } \\
\text { political brokerage, ex- } \\
\text { ternal influence }\end{array}$ & $\begin{array}{l}\text { Organization operates on } \\
\text { trial and error; few } \\
\text { problems are solved by } \\
\text { resolution; rather by } \\
\text { "flight" or "oversight" }\end{array}$ \\
\hline $\begin{array}{l}\text { Cycle of decision- } \\
\text { making }\end{array}$ & $\begin{array}{l}\text { Problem definition; } \\
\text { search for al ternatives; } \\
\text { evaluation of alterna- } \\
\text { tives; choice; implemen- } \\
\text { tation }\end{array}$ & $\begin{array}{l}\text { As in bureaucratic } \\
\text { model, but in addition } \\
\text { stresses the involve- } \\
\text { ment of professional } \\
\text { peers in the process }\end{array}$ & $\begin{array}{l}\text { Emergence of issue out of } \\
\text { social context; interest } \\
\text { articulation; conflict; } \\
\text { legislative process, imple- } \\
\text { mentation of policy; feed- } \\
\text { back }\end{array}$ & $\begin{array}{l}\text { Random activity, dependent } \\
\text { on problems, solution and } \\
\text { participants meeting at } \\
\text { choice opportunities }\end{array}$ \\
\hline
\end{tabular}


organization. However, not all PMS's reach that goal since they may be terminated at any stage before arriving at a policy statement. The PMS exists only to develop a response to the identified issue and although it may overlap with many other PMS's in the organization, it is considered to have ended when either a policy is accepted, activities relating to the issue cease, or the issue has been distorted to the point where it is judged to be a new issue.

Any number of overlapping systems may be operating concurrently within an organization and the aggregate of these systems could be called the "policy system" of the organization. This larger system includes among its components a number of more or less permanent organizational structures, such as departments, committees, or councils, which have designated roles to play in PMS's that evolve in response to specific issues. These structures are not PMS's in themselves; rather, they interact with each other and with less permanent groups or individuals in what Simmons et. al. (1974:461) referred to as a "random, multi-channelled" manner resulting in the identification of issues and the development of policy.

Within the PMS the major categories of components are processes, actors, issues and outcomes. In order to analyze and understand a system, the main components in each of these categories must be identified and described along with the in teractions or linkages among the components. In addition, the environment must be described in sufficient detail to gain an appreciation of its effects on the development and operation of the system. Whereas detailed procedures for implementing the PMS model were developed and reported elsewhere (Taylor, 1980 ) in this presentation, only a general description of the technical aspects of the model will be given.

In addition to a detailed narrative of the case, the model utilized a number of conventions for symbolically representing the events of the policy-making process. The first objective in developing these conventions was to represent the sequence of events in the system along with the major influences from the environment. Figure 2 demonstrates how two levels of systems (the university and the PMS) are located within the community environment and allows for the representation of a chain of events within the system. The boundaries of the systems are represented by broken lines, indicating their permeability and the arrows indicate the flow of issues and information into and out of the system. This rather simple scheme also allowed for the documentation of contiguous policy-making systems which overlap with the focal PMS either through common issues or actors.

While the convention described above focused on the temporal dimension of the system there was also a need to more fully represent the complexity of the system during any particular event. Figure 3 can be considered a cross section of the process and was used in the study to indicate how actors were related to one another and to the environment. The environment was broken into the three main segments of constituencies, administrative structure and contiguous policymaking systems. The relationships between the actors and particular elements of the environment are shown by broken lines. The relationships among actors represent not only formal linkages, such as memberships on committees, but also 


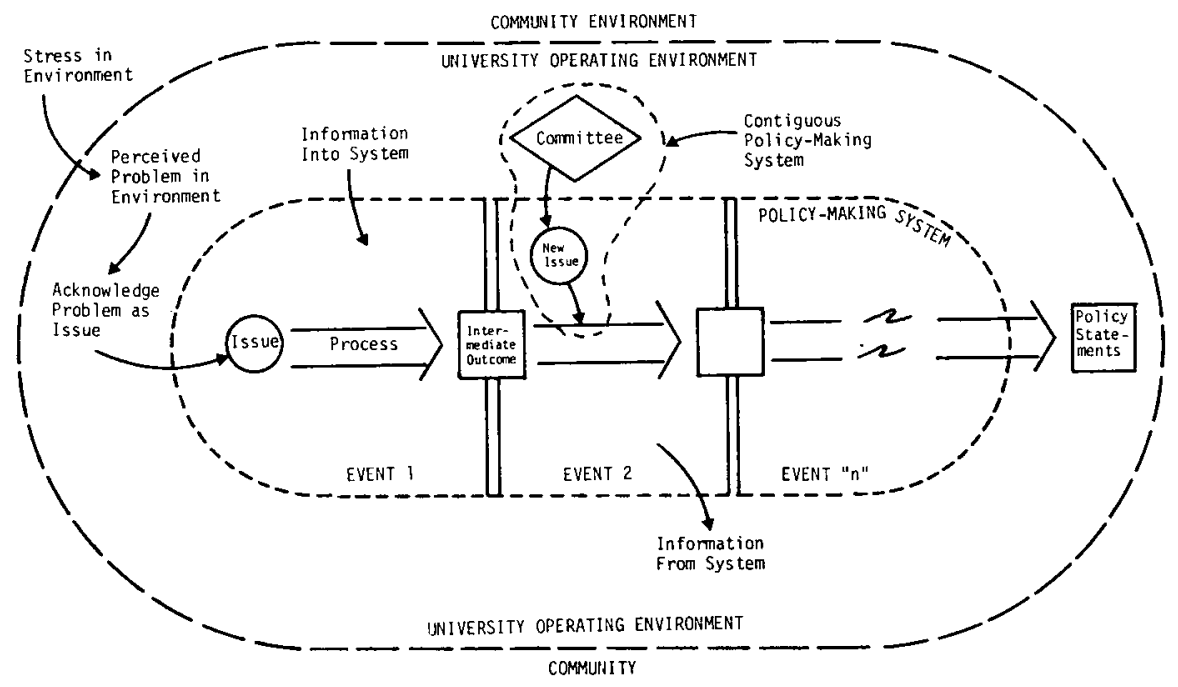

Figure 2 A policy-making system: Focus on process

represent informal or social relationships which might determine a common position on an issue.

\section{A CASE IN POLICY-MAKING}

These conventions, along with a narrative description, were used to document and analyze a major policy-making process at The University of Calgary. This case involved the re-examination of faculty appointment and promotion policies in response to decreasing enrolments and financial support.

The following is a brief description of the process as it proceeded from the identification of an issue through to the adoption of a policy statement.

\section{Event 1: Problem Recognition and Diagnosis}

The case began in December of 1977 when the vice-president presented a problem to the $\mathrm{U}$ of $\mathrm{C}$ president. The vice-president described the situation as a resource reallocation problem resulting from increased pressure on the budget for academic salaries at a time when government grants were barely keeping pace with the rise in inflation. The president accepted the problem as a legitimate policy issue and advised the vice-president to develop a policy with the assistance of the dean's council (DC). This event marked the initiation of a policy-making system as defined in the conceptual model. A problem was identified in the operating environment, given status as an issue, and a procedure was then determined for arriving at a policy statement.

Event 2: First Development Phase

In February, 1978, the VP presented to the dean's council a recommended policy statement for their consideration. This policy statement contained some very 


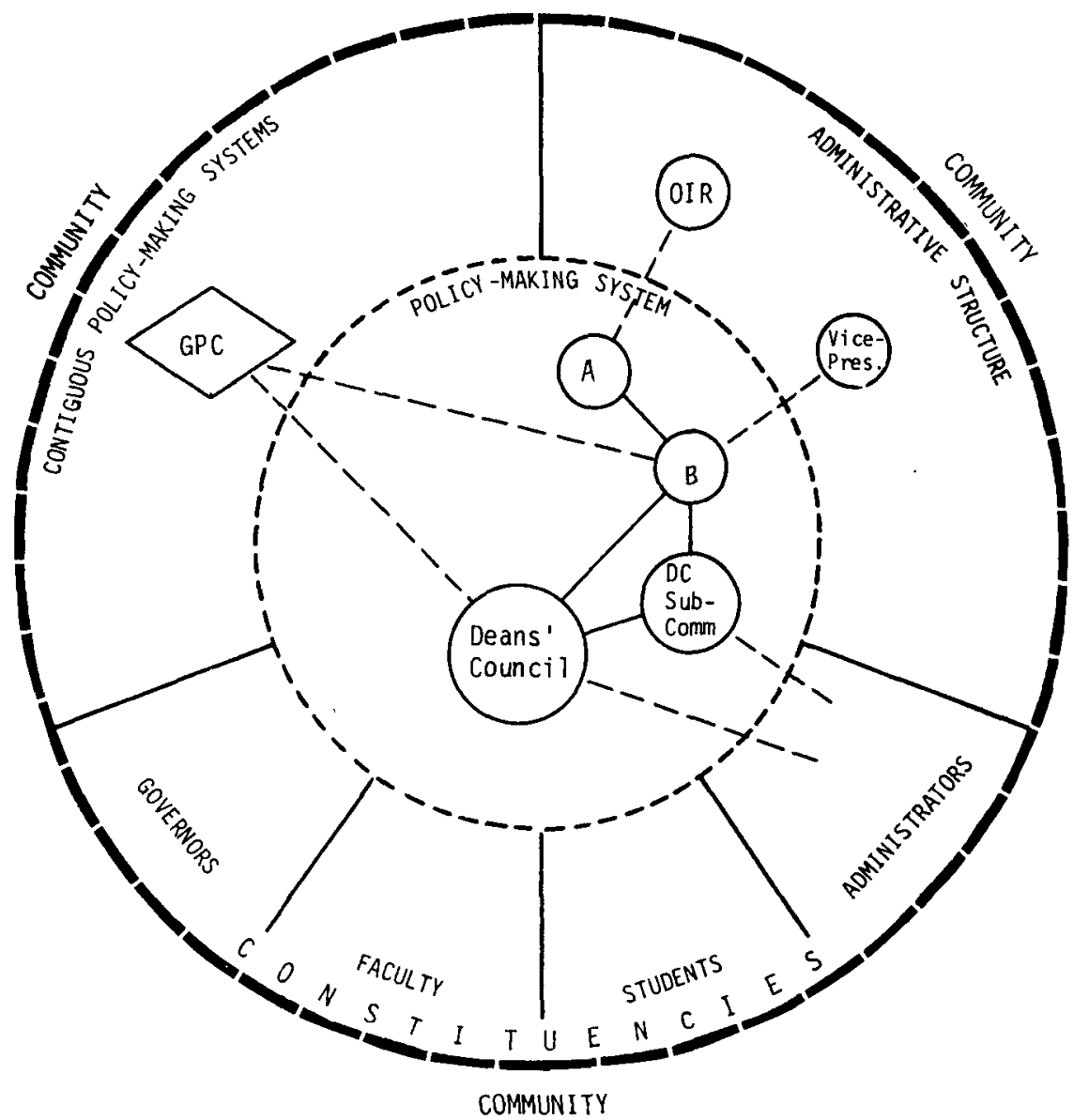

\section{Legend}

GPC - General Promotions Committee

OIR - Office of Institutional Research

A - An individual representing OIR

$B$ - The incumbent Vice-President

Figure 3 A policy-making system:

Focus on actors

specific proposals which met with considerable resistance in the DC and, following debate, a sub-committee was appointed to report back with further recommendations. The report of the sub-committee, a significant modification of the original proposal, was subsequently adopted and a formal policy statement was issued. Implementation of the policy was to begin immediately. 


\section{Event 3: The Major Interrupt}

Within days of the decision of the DC, the faculty association (TUCFA) president challenged the authority of the $\mathrm{DC}$ to adopt policy relating to the appointment of academic staff. The challenge was delivered directly to the DC and also on the floor of the general faculties council (GFC) through a motion proposed by the TUCFA president. This challenge resulted in further modifications of the policy statement. These modifications satisfied the TUCFA president and he agreed to withdraw his motion from the GFC agenda and replace it with another. The new motion called for the appointment of an ad hoc committee which would recommend policy to GFC on the broad issue of faculty appointments.

\section{Event 4: Second Diagnosis and Development Phase}

During April, 1978, the striking committee of GFC appointed the ad hoc committee on appointments policy under the chairmanship of the vice-president. The committee was composed of several key actors from the preceding events, including the TUCFA president and two deans who served on the DC subcommittee, plus a number of actors new to the policy-making system. The committee met briefly during the spring, recessed for the summer, and resumed meetings in the fall session of 1978 . Since the meetings throughout this period were held in camera, the university community was not aware of their recommendations until a formal report was submitted to the GFC executive in February, 1979.

\section{Event 5: Evaluation}

The major evaluation took place after the GFC executive decided to circulate the report to all academic departments for comment before forwarding it to GFC. During this period a great many departmental and faculty meetings were held to consider the effects of the policy proposals and to draft responses to GFC. The GFC executive received, compiled and distributed all responses to members of the GFC. The responses were many and varied, reflecting the concerns of both individual faculty members and academic units who would be affected by the recommendation.

\section{Event 6: Choice and Authorization}

During this event, the GFC and the board of governors (BOG) had the major roles. GFC considered all recommendations of the committee and in the case of those which were "academic," gave the final authorization for the policy statements. When recommendations fell under the jurisdiction of the BOG, GFC passed them on only after consideration and endorsement by its own members. The system was essentially terminated in October, 1979.

\section{ANALYSIS OF THE CASE}

Data concerning The University of Calgary case study were collected through two primary sources - documents and personal interviews. Initially, all accessible, relevant documents were examined and information from the documents was 
analyzed in order to determine the broad boundaries of the policy-making system (PMS). Following this analysis a tentative list of key actors was drawn up and each individual was interviewed using a loosely structured interview guide. The interviews were in considerable depth and in most cases the responses were recorded on audio tape for later analysis. Actors were probed to provide not only factual data but also their perceptions of the attitudes, influence, motives, strategies and actions of other actors. Those on the initial list of participants were also asked to name other key actors who were subsequently interviewed using a similar approach. During the interviews additional documents came to light and were included in the analysis. The voluminous amounts of data collected through this procedure were analyzed, digested and reported using the framework established in the PMS model. The detailed account of the case is not included here, rather, the remainder of this article will concentrate on the conclusions reached in the study. The initial conclusions assessed the degree to which each of the proposed models of university policy-making explained the phenomena observed in the case.

\section{The Bureaucratic Model}

Although this model did not apply in the ideal form as originally proposed, several observations can be explained through its application. For example, the identification and diagnosis of the issue was undertaken initially by the officer responsible for that operating area. He adopted a rational approach through the collection of pertinent data, examination of alternative solutions and selection of the most promising policy. In another instance, the president's actions conformed to the bureaucratic model when he decided to bypass the General Faculties Council and take a proposed policy directly to the Board of Governors. He apparently assumed that he had the authority for such action because of the position of his office in the hierarchy.

Therefore, it was concluded that the bureaucratic model was helpful in the explanation of university policy-making in this instance because specific examples of bureaucratic phenomena were identified.

\section{The Collegial Model}

Most actors in the study subscribed to the principle of collegiality and supported it as the most appropriate model for university governance. However, no evidence was found of a truly consensus model of decision-making in the policy-making system. Even in the operation of the major committee, where no formal voting procedures were adopted, certain members felt the process was one of individuals submitting to the apparent will of the majority, rather than decision by consensus.

Another implication of the collegial model is the existence of a "community of peers" within which individuals can influence the decision-making process on an equal basis. In this study it was apparent that the influence or power exerted by individuals differed depending on the constituency or administrative position they represented. The degree of influence appeared to be a function of the accessibility of information, the experience of the individual, and the time available to devote to the process. Since the administrators had advantages in all 
three of these areas, it is understandable that they exercised more power than faculty or student participants. To the extent that this power imbalance exists in universities, it is difficult to accept the applicability of the collegial model.

The acceptance of collegiality as a normative model of policy-making has had obvious effects however, particularly on the structure of the permanent decisionmaking bodies within the institution. Councils and committees, such as the General Faculties Council, have representatives of faculty, students and administration, which presumably creates an opportunity for all constituencies to equally influence decisions. This study tends to demonstrate, however, that the creation of such opportunities does not necessarily result in a "community of peers" when measured by the degree of influence or power of each participant. Therefore, the collegial model, as defined in the literature, is only operative in university policymaking as a normative guide in the design of participative decision-making groups. This may reflect the general decline in collegiality on a model of university governance which Karol and Ginsberg (1980) attribute to a variety of pressures both internal and external to the institution.

\section{The Political Model}

This model represents the university as a political system within which definable interest groups compete for resources and power. The applicability of the model will be assessed through an examination of the six underlying assumptions of the political model.

1. Few people become involved in the process. This assumption was borne out by the study. The number of key actors (those directly involved in the decisionmaking process) tended to remain small until the issue was brought to GFC and BOG for authorization. In fact, the network did not expand much beyond the initial network of ten to twelve individuals.

2. Those who participate move in and out of the process. This "fluid participation" was found to be a feature throughout the evolution of the system. The only actor who was involved through all major events was the vicepresident, the key actor.

3. Interest groups, with differing goals and values, exist in universities and participate to the degree their interests or relative positions are threatened. Throughout the process, the TUCFA representatives perceived the protection of this group as the major issue and were willing to support other proposals only as long as their security was not threatened. One other interest group, the students, did not perceive a threat in the policy issues or proposals and did not participate in the process until invited to do so. Their participation tended to be of low influence and lasted for only the development phase of the policy-making system. The study, therefore, supports the assumption that interest groups exist and their participation is directly related to the perceived threat to their security.

4. In the university, conflict is natural and can be viewed as a positive force promoting desirable change. Actors in the study tended to view conflict as a "fact of life" in university governance but did not explicitly ascribe a negative 
or positive value to it. The decision-making mode, particularly in Deans' Council and the committee appeared to be one of "conflict avoidance" which may indicate an unstated belief that conflict is not a positive force and should be avoided through compromise. Therefore, the study supports the assumption that conflict is "natural" in a university setting but that it is not viewed by participants in policy-making as having a positive value.

5. The exercise of power by interest groups places severe limitations on formal power, leading to compromise decisions. The power of the administrators to make unilateral decisions was apparently limited by the action of interest groups in this case. The final policy statements authorized by GFC and BOG, however, contained all the mechanisms sought by the key administrators in the first instance. The president, representing the formal power structure, also asserted the right of the administration to take unilateral action should the GFC not support certain key policy proposals. It is, therefore, not completely clear that the exercise of power by the faculty interest group restricted the formal power of the administrators. What is clear is that action by the faculty constituency lengthened the process by causing the issue to be considered by a new group of actors in a completely different arena. Consequently, the assumption is supported to the extent that the administrators were unable to adopt a policy within their own relatively short time frame but is not supported to the extent that the administrators did eventually achieve their stated policy objectives.

6. External interest groups exert a strong influence over the policy-making process in universities. Data collected in this case did not reveal any direct influence by external interest groups in the policy-making system. However, the perceived threat of increased government control or intervention in the internal affairs of the university was expressed several times by certain individuals and may have indirectly influenced the process. This expression of concern tended to be used as a justification or motivation for taking decisive action on a policy issue. Although the vice-president employed such rhetoric in public statements, he personally believed that the actual threat of government interference was extremely remote.

The assumption, therefore, is supported only to the extent that the perception of potential overt action by an external interest group can influence the behavior of actors in a policy-making system.

In summary, the study supported, in whole or in part, each of the six underlying assumptions of the political model. It can therefore be concluded that within the policy-making system in this study, the political model was operative and was valuable in providing an explanation of many of the observed phenomena.

The Organized Anarchy Model

For this model to apply there should be evidence that the organization is an organized anarchy (that is, has problematic goals, unclear technology and fluid participation of members) and employs the "garbage can" model of decisionmaking.

The study definitely supported a conclusion that the university is an organized 
anarchy as defined in the literature. The goals were often in conflict or were difficult to clearly define; the individuals were unsure of the optimum method of accomplishing their goals; and, as was shown in the discussion of the political model, there was fluid participation of members. There was also evidence that the garbage can model of decision-making was operative. For instance, particular recommendations in the major committee report were closely related to or "stuck to" specific actors; however, these recommendations were not closely related to the major issues and consequently were not authorized for adoption. In the garbage can model this would be an example of "oversight," where a choice is made without attention to existing problems.

The case can also be viewed as support for the hypothesized relationship between organizational slack and the decision structure of the organization (Cohen, March, Olsen, 1972: 12). The process was initiated because of a reduction in organizational slack (i.e. restricted funding) and resulted in a centralization of decisions relating to academic appointments, or a shift toward a hierarchical access structure. This relationship is consistent with the model.

There is contrary evidence, however, which suggests the decision-making processes were not as random or haphazard as is suggested in the organized anarchy model. For instance, in the initial stage of problem identification and diagnosis, the administration conducted a systematic study of the quantitative dimensions of the problem, examined solutions at other institutions and projected the future impact of the problem. In another instance, one of the threatened organizational units, the Faculty of Continuing Education, developed a deliberate strategy for influencing the process and managed to turn the situation to their own benefit. Neither of these events was a random occurrence but rather, was the result of conscious decisions by those within the system. In fact, the strategies used appeared remarkably consistent with advice given by Padgett (1980) in his discussion of "Garbage Can Hierarchies."

The conclusion, therefore, is that while the organized anarchy model does apply to the extent that many observations appeared to fit within the model's definition, there are other phenomena which cannot be adequately explained by the model.

In summary, the four proposed models of policy-making reviewed above were all to some extent applicable and useful in the explanation of policy-making in universities. However, the models, either individually or in combination, do not provide a complete explanation of the phenomena observed in the study. In particular, these models fail to accommodate the dynamic nature of the process, the mix of decision-making approaches that exist and the unpredictable influences of the environment on the policy-making process.

\section{THE NATURE OF POLICY-MAKING: A REASSESSMENT}

The policy-making system model developed for use in the study was an attempt to provide a framework or methodology for systematically analyzing policymaking and was not intended as a replacement for previously proposed models. It appears, however, to avoid some of the problems identified with other pro- 
posals and may be considered as an alternative method of conceptualizing the policy-making process. The PMS model recognizes that the methods of decisionmaking utilized in policy-making will vary depending on the issues, actors or some environmental condition. It accommodates virtually any sequence of events within the process rather than assuming them in either a rational or a haphazard process. It does not demand logical consistency among actors in terms of issue or goal identification nor between issues and policies. Finally, the PMS model provides for the linkages among the many policy-making processes which occur at any time within a complex institution such as the modern university.

The data analyzed in the study and the policy-making system conceptual model suggested the following definition:

Policy-making in universities can be viewed as a network of policymaking systems, each of which is temporary in nature and is initiated in response to stresses in the institution's operating environment. Each policy-making system is itself a network of issues and actors who function in interaction with their environment, progressing in a heuristic manner toward a vaguely defined policy goal. (Taylor; 1980, 224).

This definition embodies a number of characteristics of policy-making that invite elaboration. The concept that the policy system of an institution is made up of a network of temporary systems, each responding to a specific environmental pressure is contrary to the traditional view, particularly within a bureaucratic model. Practitioners and researchers alike have viewed the policy system as the somewhat static interrelationship of officially authorized individuals and groups. Within this static model, the process of policy development was clearcut: simply insert an issue at the proper location in the structure, the issue will then be processed through a series of predetermined steps, and a policy will finally be authorized by the appropriate individual or group. This view of policy-making led to the logical conclusion that a set routine for the development of policy could be designed for each class of policy issue. For example, within a university, academic issues would be routed through GFC to a standing committee, back to $\mathrm{GFC}$, and then on to the Board of Governors for final authorization. Likewise, financial issues would follow a predetermined path involving individuals, committees, and councils. Millett (1980) provides an elaboration of this view in his discussion of the management and governance of the university.

Contrary to this traditional view, the policy-making system model suggests that the process cannot be predetermined and that the actors in the system should be prepared to react to input from the institution's operating environment that could alter the chain of events in the system. This view puts more emphasis on the design of a process that suits a specific issue and less emphasis on developing a grand design that is expected to handle a whole class of issues. This model recognizes the necessity for having permanent, legitimate, policy authorizing bodies such as General Faculties Council or the Senate but suggests that these structures should be recognized as only single components in a system for the formulation of policy. The PMS model also suggests that the process, even for a 
single issue, cannot be designed in any precise manner. The process is described as heuristic (rather than algorithmic) which implies that it is bounded by certain constraints and principles but within these confines is free to move on any number of paths, often through a number of iterations. Failure to recognize this characteristic of policy-making could obviously lead to frustrated attempts to exert too tight control over the process.

The definition proposed above also emphasizes that a PMS is initiated only in response to a stress in the institution's operating environment. This implies that although policy-making is a continuous process within the university, issues are not recognized until the institution is under some type of environmental stress be it economic, political, or social. Further, it appears that a kind of "institutional inertia" or "institutional conservation" as suggested by Astin (1976), exists which inhibits the recognition of an issue or the development of a policy unless the stress is perceived to be sufficiently large and threatening. This may explain why some issues receive immediate response and swift resolution while others apparently get bogged down in endless "loops" or iterations. Unless the key actors perceive the issue as threatening either to themselves or their immediate organization they will not expend the energy necessary to move the process along, continually overcoming the institutional inertia.

Another feature of policy-making systems is the flow of information between the PMS and the institution's operating environment. The actors in the system are continuously receiving information from people in the institution who are not directly involved in the process and are often providing information back. While this information exchange is often a rather haphazard and informal process, that need not be the case. Actors in the system can arrange opportunities and appropriate channels for the flow of information. These opportunities can take the form of public hearings, invitations for formal responses to policy proposals, or regular reports on the progress of the policy-making activity. Failure to open such channels can result in major interruptions and delays in the process (as happened in the $\mathrm{U}$ of $\mathrm{C}$ case) and may in the end result in less effective policies. Policies developed under a veil of secrecy often invite strong negative reaction, particularly when the issues are highly politicized. Therefore, the interaction with the environment of the PMS should be recognized as inevitable and should be directed in such a manner as to make appropriate use of the institution's total information resources and to minimize the possibility of serious disruption to the policy-making process.

A final feature noted in the proposed definition of policy-making is that within a PMS neither the goals of individuals nor the issues identified in the system need be consistent. Individuals do not necessarily agree on what major issues they are addressing nor do they agree on what goals the new policies should attempt to accomplish. This calls into question Corson's advice to trustees (Ingram; 1980) which urges them to become involved in the process of developing mission statements and clarifying goals - an activity with little reward if the policy makers choose to ignore or re-interpret such statements. Lack of agreement may inhibit 
progress toward new policies but, as demonstrated in the research, does not prohibit agreement on policy statements. One possible explanation for this seeming inconsistency may be in the interpretation of the policy statements themselves. Individuals tend to attribute differing characteristics to policy proposals and consequently may each assume that the policy addresses their own identified issue to the exclusion of others. In addition, as Lindblom (1959) pointed out, policies are often deliberately stated in vague terms in order to permit a variety of interpretations, thus reducing the prospect of serious disagreement.

The conclusions reached in the study of policy-making at The University of Calgary suggest that policy-making is a complex process which defies categorization into simple models of process or structure. The challenge to researchers is to continue to illuminate the dimensions of the phenomenon while practitioners are challenged to optimize their effectiveness within a system over which they may have little direct control.

\section{REFERENCES}

Astin, A.W. Academic Gamesmanship. New York: Praeger, 1976.

Baldridge, J.V. Power and Conflict in the University. New York: John Wiley \& Sons, 1971.

Cohen, M.D., \& March, J.G. The American College President. San Francisco: McGraw-Hill, 1974.

Cohen, M.D., March, J.G., \& Olsen, J.P. A Garbage Can Model of Organizational Choice. Administrative Science Quarterly, 1972, 7, 1-25.

Ingram, T.R. Handbook of College and University Trusteeship. San Francisco: Jossey-Bass, 1980.

Karol, N.H., \& Ginsberg, S.G. Managing the Higher Education Enterprise. New York: John Wiley, 1980.

Lindblom, C.E. The Science of Muddling Through. Public Administration Review. 1959, 19, 79-88.

Miller, J.G. Living Systems. New York: McGraw-Hill, 1978.

Millett, J.D. Management, Governance, and Leadership. New York: AMACOM, 1980.

Millett, J.D. The Academic Community. New York: McGraw-Hill, 1962.

Padgett, J.F. Managing Garbage Can Hierarchies. Administrative Science Quarterly, 1980, 25, 583-604.

Simmons, R.H., Davis, B.W., Chapman, R.J.K., \& Sager, D.D. Policy Flow Analysis: A Conceptual Model for Comparative Public Policy Research. Western Political Quarterly, 1974, 27, 457-468.

Taylor, W.H. The Evolution of a Policy-Making System: A Case in University Governance. Unpublished Ph.D. Dissertation, The University of Alberta, 1980.

von Bertalanffy, L. General Systems. Yearbook of the Society for the Advancement of General Systems Theory, 1956, 1, 1-10. 